\title{
ACUMULACIÓN POR DESPOSESIÓN DENTRO DE LA LÓGICA RENTISTA EN BRASIL
}

\section{Eliane Tomiasi Paulino*}

RESUMen: Partiendo de marcos conceptuales asociados a la acumulación por desposesión, el artículo se posiciona en el caso brasileño, país que en términos proporcionales representa los mayores índices de concentración del suelo en el mundo e incomparable desigualdad social. La monopolización del suelo es, al mismo tiempo, producto y productora de relaciones de poder asimétricas, añadiendo un elemento que complica la situación: la ausencia de distinción de clases en el sentido clásico, una vez que legalmente los propietarios rurales tienen negocios urbanos y los capitalistas son propietarios de grandes fracciones de tierras en el país. La apropiación de la tierra se dedica menos a fines productivos y más a especulativos, lo cual alude a que en el país existe una modalidad dominante del capitalismo denominado «rentista», dentro del cual los despojos ambiental y territorial son estructurados. Su legitimación reposa en la supuesta racionalidad virtuosa de la agricultura a escala que justificaría la manutención del monopolio de la tierra. Se solidifica una alianza tierra-capital, cuyo esfuerzo de ocultar la ineficiencia de la gran propiedad ha sido exitoso, pues la reforma agraria ha desaparecido de la agenda política, al mismo tiempo que van destruyéndose los viejos marcos constitucionales relativos a los derechos ambientales y territoriales a quienes tienen derecho. Lejos de ser ineficientes, como hacen creer los que necesitan de argumentos productivistas para seguir concentrando la tierra, riqueza y poder, los campesinos son más eficientes y se justifican los esfuerzos analíticos que revelan a la sociedad esa paradoja, como forma de confrontar el pacto oligárquico que, en nombre del desarrollo, requiere modalidades de despojo ambiental y territorial contrarias a la soberanía y autodeterminación nacional.

PALABRAS ClAVEः agricultura capitalista, agricultura campesina, capitalismo rentista, cuestión agraria-ambiental, despojo territorial.

* Profesora de la Universidade Estadual de Londrina, Brasil.

Traducción del portugués de Guadalupe Margarita González Hernández. 
ABSTRACT: Keeping in mind conceptual frameworks associated with accumulation by dispossesion, this article takes up the Brazilian case, a country that in proportional terms represents the highest indices of land concentration in the world, with unparalleled social inequality. The monopolization of land is, at the same time, the product and producer of asymmetric power relationships, with an additional element that further complicates the situation: the absence of class distinction in the classic sense, given that rural ladowners are the legal owners of urban businesses and that capitalists are the owners of huge swaths of land across the country. The appropriation of land is desired less for productive reasons and more for speculation, an indication that there exists in the country a dominant mode of capitalism, known as rentier capitalism, within which environmental and territorial dispossession are structured. Its legitimacy lies in the supposed virtuous rationality of agriculture on a scale that justifies monopolistic landholding. It solidifies the land-capital alliance, whose ability to obscure the inefficiency of large estates has been successful, with agrarian reform disappearing from the political agenda, while longstanding constitutional structures tied to environmental and land rights continue to be destroyed. Far from being inefficient, as those who need productivist arguments to continue concentrating land ownership, wealth and power would have us believe, peasant farmers are more efficient. Analytical efforts that unveil this paradox to society in general are necessary as a way to confront the oligarchical pact that, in the name of development, requires methods of environmental and territorial displacement contrary to national soveriegnty and self-determination.

KEYWORDS : capitalist agriculture, peasant agriculture, rentier capitalism, agrarian-environmental question, land displacement. 


\section{INTRODUCCIÓN}

$\mathrm{E}$ 1 fenómeno de la urbanización a escala mundial impacta los debates de manera que la temática del campo casi siempre aparece como una cuestión secundaria, ya sea por la separación física de la mayor parte de la población del planeta de este espacio de vida, trabajo y producción, o por la peculiar densidad del espacio urbano, que evidencia las contradicciones de lo cotidiano y genera mayor visibilidad.

En Brasil, el predominio de las ciudades contribuye a instalar nociones de jerarquía territorial aparentemente lógicas, ya que favorece la correlación automática entre densidad y la supuesta determinación de las relaciones de poder que la originan en el interior de la cual se mueve la sociedad. Por ello, no es raro considerar al campo y la ciudad como espacios disociados y pasivos de una jerarquización orientada por criterios cuantitativos. Con todo, esta dicotomía es inapropiada, una vez que en el campo se origina la mayor parte de los valores de uso indispensables para la sociedad, los cuales se transforman en valores de cambio para atender al mercado que se concentra fundamentalmente en las ciudades. La concentración y dispersión son contenidos de lo urbano y lo agrario, instruidos por la lógica de la acumulación capitalista, cuya intensidad y asimetría varían en el interior de las sociedades, siendo objetivo del presente trabajo demostrar cómo se manifiesta en Brasil, un país eminentemente urbano, más profundamente marcado por la hegemonía de un pacto oligárquico.

Pareciera que la densidad urbana, que favorece una plena realización de valor, es sustentada por los bienes provenientes del campo, cuya conversión en mercancías es a través del proceso de valorización impuesto por el trabajo, situación que ha sido observada ya por Marx (1974) al asumir que todas las formas de riqueza tienen origen en el trabajo y la tierra. Siendo así, este trabajo privilegiará los mecanismos y evolución de la apropiación privada de la tierra, elemento irreproducible y, al mismo tiempo, determinante para la dinámica de la riqueza en una sociedad, 
razón por la cual los criterios de división y acceso la afectan decisivamente.

A pesar de las elevadas tasas de urbanización e importancia de la economía urbano-industrial, Brasil es considerado uno de los grandes productores agrícolas del mundo, con participación destacada en soya, maíz, café, naranja, azúcar, pollo y carne bovina, entre otros. Paralelamente, es el principal poseedor del mayor patrimonio ambiental tropical del planeta, cuya biodiversidad y participación en los procesos de ciclo de vida de agua dulce y regulación del clima influencian dinámicas globales. En tanto, los propietarios privados que poseen la concesión para su administración no lo perciben así, razón por la cual las cuestiones agrícola, agraria y ambiental no están disociadas y, actualmente, son el centro de nuevos conflictos.

El título de propiedad de la tierra supone intereses trascendentales a las debilidades del reparto de la tierra, forjando una disputa entre la conservación y devastación de la naturaleza, una vez que los bienes comunes, como el agua, aire, variabilidad genética y muchos otros están vinculados con el suelo. Alternativamente, éste se encuentra bajo estricta elección de quien la posee. Aunque la institución de la propiedad privada promueve la prohibición de destruir todo lo que pueda ser entendido por naturaleza, también es verdad que el derecho de propiedad desde su origen se ha visto limitado por las luchas sociales, movidas por la tentativa de salvaguardar la función social de la tierra, hecho que merece una atención especial, teniendo en cuenta su profunda negligencia en Brasil.

Tal complejidad requiere una reflexión que va más allá de elementos de orden coyuntural porque los elementos estructurales son, por demás, decisivos, siendo el propósito investigar cómo se desdoblan en términos territoriales. En ese sentido, se destaca la flexibilización de la legislación ambiental, en particular del Código Florestal Brasileiro, una herramienta que necesitaban los terratenientes para simular la adecuación ambiental de tierras bajo su control, como forma de continuar extrayendo recursos 
naturales y, al mismo tiempo, subsidios del Estado, en nombre de la producción agrícola.

Las leyes ambientales de avanzada existen desde el periodo colonial, mas no impidieron la depredación ambiental típica del patrón agrario exportador. Con los cambios en la coyuntura política, como la democratización de la sociedad, eventualmente las convirtió sólo en amenazas a quienes nunca han cumplido, porque el Estado no hizo nada para que esto ocurriera. Fue evidencia del control social tardío de un Estado con una legislación moderna donde la oligarquía temió su práctica y terminó por transgredir las leyes. Al final, para no seguir quebrantando leyes, fue necesario cambiarlas para mantener el patrón extractivista sobre el cual reposa su riqueza y poder y generar disputas que van ocurriendo desde el fin del régimen militar.

Desde inicios del periodo democrático, ahora vigente en el país, tenía en el régimen jurídico los instrumentos de su consolidación. En ese contexto florecen las luchas sociales que dieron visibilidad a la devastación ambiental y violencia en el campo, y la exposición inédita de los métodos capitalistas de ocupación del Amazonas, uno de los factores esenciales para aumentar la presión sobre el Estado para hacer cumplir la legislación ya existente, aunque nunca alcanzó el pacto oligárquico, históricamente nutrido por la dilapidación de las riquezas naturales y degradación del trabajo.

Ha sido una batalla desigual al no haber equivalencia de fuerzas entre la sociedad civil organizada y la oligarquía con tradición autoritaria y patrimonialista de base agraria, cuyo legado sigue siendo la enorme dificultad de mantener en la agenda política el debate sobre la necesidad de la reforma agraria e incluso el mantenimiento constitucional de los derechos territoriales de los pueblos indígenas y poblaciones tradicionales.

Más que persistencia, se verifica la profundización de la hegemonía de base oligárquica, en la cual los dueños de la tierra, sean burgueses con negocios agrícolas o viejos militares, afrontan la legislación ambiental, la laboral, los derechos civiles, la Constitución, en fin, todo lo que 
representa un obstáculo para ser libres de poseer la tierra y lo que está en ella.

La centralidad de este texto radica en el desarrollo más reciente de esa lucha desigual entre el bien común y el control oligárquico, la cual procura dar prioridad a problemas que emergen con fuerza en la actualidad, como las cuestiones indígena, agraria y ambiental, que en la práctica se derivan de la hegemonía de clase sobre distintas esferas del aparato de Estado. En el contexto de adoctrinamiento de la sociedad al consumo, en vista del progreso económico coyuntural, gracias a la expansión del crédito y mejoras en el ingreso salarial ocurridos en la última década, aparece como una droga en las luchas, al mismo tiempo que el crecimiento de la producción agrícola es invocado para diseminar la idea de que dichas luchas contra las injusticias agrarias son actos de terrorismo ocasionados por enemigos de la patria y que deben ser aplastadas.

\section{MONOPOLIO DE LA TIERRA Y VULNERABILIDAD SOCIOAMBIENTAL}

En Brasil, la agresión de clases en torno a la tierra fue central en la constitución del Estado moderno, eso sin mencionar la formación colonial que le antecede, donde el balance ha sido positivo para un grupo tan reducido como eficiente en perpetuar el monopolio de la tierra. Eso no significa la eliminación de la apatía de los campesinos, cuya probabilidad de manifestación parece ser más coherente con la lectura de Wolf (1976) sobre su realce en las revoluciones contemporáneas, producto de la inmovilidad de su condición política previa, como expresó Kautsky (1980), entre otros.

La prevalencia del imaginario colectivo sobre la idea de ausencia de insurrecciones y guerras campesinas en Brasil es producto de algunos factores; uno de ellos está relacionado con la geografía de luchas: fue en la sociedad colonial donde el criterio de exclusión de los campesinos del derecho a un título de concesión de tierra los expulsó de las zonas po- 
bladas, prevaleciendo la ocupación dispersa y altamente vulnerable al despojo de la propiedad.

Esa exclusión está en el principio a perpetuidad del desplazamiento determinado por el grado de interiorización de la economía colonial, cuando los llamados hombres de sangre pura se consideraban propietarios de esclavos y con prestigio político para reivindicarse mediante cartas de adjudicación concedidas por la administración colonial. Bajo este sistema, renovado con cada cambio coyuntural, se sustentó el pacto oligárquico que mantiene al país como el de mayor concentración de la tierra en el mundo.

Ese pacto ayuda a explicar la invisibilidad de las luchas campesinas en la historia oficial, mismas que son igual de violentas a la Guerra de Disputa (1912-1916), la más larga y con mayor número de víctimas. Dentro de la estrategia de expansión del ferrocarril, el Estado donó aproximadamente 1.8 millones de hectáreas de tierras a una empresa estadounidense que se encargaba de la construcción de una de las rutas en la región sur. Pero las tierras donadas no estaban deshabitadas; estaban ocupadas desde hacía más de un siglo por campesinos que ahí se instalaron, producto del mecanismo de exclusión anteriormente mencionado.

La tentativa de garantizar la posesión de tierras culminó con una amplia organización de campesinos, lo que movilizó gran parte del efectivo Ejército brasileño. La guerra duró cuatro años y terminó sin que jamás fuesen restituidas a los campesinos las fracciones de tierra que les pertenecían. La pacificación requerida por el invasor extranjero, que demandaba seguridad de dominio, terminó con el exterminio de todos los combatientes de la región conflagrada, estimado en 30 mil personas (Fraga, 2010; Galeano, 1989).

Esa fue una de las muchas insurrecciones campesinas ocurridas desde la abolición de la esclavitud (1889) hasta antes de la década de los sesenta del siglo $\mathrm{xx}$, momento en que fue instaurada la más larga $\mathrm{y}$ sangrienta dictadura militar en Brasil, en respuesta al movimiento campesino que más amenazó las estructuras del Estado oligárquico, las Li- 
gas Campesinas. A pesar de la represión y el exterminio sistemático de los líderes, el fundamento movilizador de las luchas - la prohibición de la tierra que trabajan - perpetuó la resistencia que, posteriormente, se constituiría en fuerza decisiva para el derrumbe del régimen militar, ocurrido en 1985.

Ese momento político expresa la reducción del campo de acción de la oligarquía y las prescripciones de la Constitución Federal de 1988 lo confirman. Promulgada sobre la égida de la democracia representativa, por primera vez, el derecho de propiedad absoluto, extensivo a todos los seres humanos de la tierra, ejercido durante casi cuatrocientos años de esclavitud, es atacado parcialmente. En el documento constitucional, el derecho de propiedad pasa a ser condicionado al cumplimiento de la función social de la tierra, apareciendo por primera vez la posibilidad de expropiar grandes propiedades para fines de la reforma agraria. Al mismo tiempo, artículos atenuantes fueron incluidos en el cuerpo del texto constitucional, al obligar al gobierno a pagar previamente el valor del mercado de las tierras expropiadas a los afectados.

Aunque ha sido producto de intensas luchas políticas, el documento constitucional es lo suficientemente dudoso para permitir grandes batallas legales que tienden a favorecer a los grandes propietarios. En la coyuntura actual, en la que el poder de movilización de los campesinos y de la sociedad civil organizada es frágil, cada vez menos se consigue hacer frente a las decisiones legales que los favorezcan, ya que el bloque oligárquico no está solamente compuesto por la clase propietaria del suelo.

Con el fin de bloquear la fuerza campesina, dentro del gobierno militar se emprendieron estrategias de cooptación de la burguesía sin relación con los agronegocios. Por medio de políticas de subsidios fiscales, fueron concedidas grandes extensiones de tierra a banqueros, corporaciones industriales y comerciales, con el pretexto de aumentar las inversiones necesarias para modernizar el campo. Se reforzó así la alianza entre la tierra y el capital, alianza que explica, por ahora, el esfuerzo exitoso para destruir los marcos jurídicos, sustituidos por una legislación 
más favorable a la legalización del acaparamiento de tierras públicas, al despojo de tierras indígenas y de poblaciones tradicionales, así como la destrucción ambiental.

Ese círculo de fortalecimiento se intensificó en la última década, cuando se observó mayor articulación ruralista en el parlamento (Gonçalves, 2012). Paradójicamente, esto coincide con el inédito ascenso de un partido de base popular que desde 2003 gobierna el país, el Partido de los Trabajadores ( $\mathbf{P T})$. Fue en ese contexto político que importantes cambios legales fueron llevados a cabo, aquí sólo se mencionan dos: sanción al acaparamiento de tierras y legalización de prácticas de crímenes ambientales. Se comienza por el segundo, que promueve la modificación del Código Forestal Brasileño, por medio de la Ley 12651, sancionada en 2012 .

Para ello, fue decisiva la estrategia discursiva en donde la deforestación sería una condición para ampliar las áreas cultivadas y mantener la posición destacada en el mercado de productos: en 2008, el país contribuyó con 5.2 por ciento de las exportaciones agrícolas mundiales (FAO, 2010). Al final, es una modalidad particular de acumulación por desposesión (Harvey, 2013), manifestada en la vulneración de los modos de vida tradicionales, en la generación de un creciente pasivo ambiental y en la distorsión del mercado de tierras en perjuicio de los agricultores más frágiles.

Brasil detenta la mayor concentración de la tierra en el mundo; a pesar de que cinco países lo superan en términos del Índice de Gini, sus dimensiones son incomparables. El de Brasil es de 0.85, el mayor corresponde a la República Checa (0.92), cuyo territorio representa apenas apenas 0.9 por ciento del brasileño (

Un ejemplo extremo de esa situación es la propiedad Curuá, localizada en el Amazonas: en 2011 todavía logró poseer un título válido de propiedad por 4.7 millones de hectáreas, ocasión en que el Ministerio Público determinó la anulación del registro de propiedad por comprobarle práctica de acaparamiento, o sea, apropiación ilegal de tierras públicas (Pinto, 2011; MPF, 2013). Cuando se identificaron otras áreas 
controladas por el supuesto propietario, igualmente de origen dudoso, su patrimonio agrario llegó a los 7 millones de hectáreas (SRFB, 2001).

Ese es un caso cuya excepcionalidad manifiesta la dimensión del monto de tierras y de prácticas territoriales heredadas del pasado colonial. Como estrategia inseparable de la creación de propiedad privada, ampliamente apoyada por el acaparamiento de tierras públicas, en la actualidad, se encuentra en la última frontera: el Amazonas Legal, ${ }^{1}$ que corresponde al 49 por ciento del territorio brasileño.

Su estampa en la región culminó en una investigación por el Congreso Nacional que, aunque con probadas acciones criminales (SRFB, 2001), no ha legislado para detener el proceso y castigar a los involucrados. Al contrario, actúa en favor de su legalización: gracias a la sanción de la Ley 11952, desde 2009 las tierras públicas indebidamente apropiadas en el Amazonas están siendo legalizadas, lo que en la práctica anula la orden jurídica vigente desde 1850, cuando se dio la institucionalización de la propiedad privada en el país. Con esa ley, el Estado renunció a 67 millones de hectáreas de tierras públicas, de las cuales apenas 8.3 millones pueden ser tituladas, caso que obedece a la Constitución, que prescribe la titulación de bienes ocupados por campesinos que sobreviven del trabajo familiar (Umbelino, 2010: 58).

Dicho acto gubernamental es el que mejor explica cómo se está desarrollando el proceso de apropiación de la renta capitalizada, una de las fases de la acumulación por desposesión. En el periodo de 2002 a 2013, el precio promedio de las tierras en el Amazonas, calculado por el sector de crédito del Banco de Brasil (citado en Monteiro, 2014) subió 509.7 por ciento, en tanto el salario mínimo subió 238 por ciento. Con menor intensidad, dependiendo de la región, esa manifestación en las propiedades rurales ha sido generalizada, siendo directamente influenciada por el aumento de las capacidades de despojo social que emana del monopolio de la tierra.

${ }^{1}$ El Amazonas Legal es el área que cubre nueve estados brasileños pertenecientes a la Cuenca del Amazonas y su zona de ocurrencia de vegetación amazónica ( $\mathrm{N}$ de la $\mathrm{T}$ ). 
La concentración del suelo, sobre todo en áreas de apropiación capitalista reciente, como el Amazonas, está asociada al trabajo esclavo, a diferentes formas de violencia contra los poseedores y a la usurpación de tierras indígenas. En el contexto de dichas embestidas, existe otro objetivo preferencial, el bosque, de donde se extrae madera de excelente calidad, cuya irreproducibilidad responde en gran medida al elevado valor comercial. A ritmo de la ley del más fuerte, el imperio de la violencia colecciona víctimas: en el periodo de 1985 a 2010 fueron asesinadas 1,033 personas solamente por conflictos agrarios en el Amazonas Legal (сРт, 2011).

Ese saldo en vidas, correlacionado con el avance de biomas tropicales, no se puede atribuir a la ausencia de leyes, porque desde el periodo colonial existe legislación forestal que, a pesar de los cambios sufridos, ha estado lo suficientemente alineada para hacer compatible eficiencia económica con conservación, aunque esta segunda dimensión nunca ha sido cumplida.

Mas la conquista de la democracia, por muy frágil que sea, es la expresión del empoderamiento de la sociedad frente a las oligarquías que, por primera vez, se han visto amenazadas por estar en evidente desacuerdo con lo que estaba prescrito en términos de conducta ambiental, particularmente con respecto a la vegetación nativa que debería ser mantenida en las propiedades y que no sucedió así.

La furia depredadora de los bosques, especialmente en el Amazonas, provocó reacciones internas y externas que obligaron al gobierno a adoptar medidas que pudieran contenerlas. Bajo ese contexto, fue promulgada la Ley de Crímenes Ambientales (Ley 9605/1998), que estableció castigo a los madereros, pero la dimensión del territorio brasileño, asociada a la falta de determinación política para cumplirla, significó que no tuviese ningún efecto práctico.

Una década después, una nueva ofensiva contra los madereros tomó forma y, por primera vez, el gobierno acabó por condicionar la liberalización del crédito agrícola a la comprobación legal de que las propiedades se encontraban ambientalmente dentro de la ley (Decreto Federal 
no. $6514 / 2008) .{ }^{2}$ Fue la posibilidad real de afectación a su condición de rentistas, el acceso privilegiado de un volumen de recursos públicos que ni el sector público ni el privado tienen en el país, lo que llevó a los ruralistas a una resuelta movilización.

En cuatro años, consiguieron cambiar radicalmente el Código Forestal, haciéndolo compatible con las actividades depredadoras y, más que eso, creando los instrumentos para cobrar de la sociedad nativa entera un impuesto adicional, denominado "servicios ambientales», en favor de los que mantienen vegetación nativa en sus propiedades. Con el paso del tiempo, una fuerte presión ejercida sobre la Presidencia de la República culminó en la promulgación de cuatro nuevos Decretos de Ley $^{3}$ prorrogando el plazo para su aplicación y manteniendo el flujo de los créditos al sector. Para 2015, continúa suspendida la exigencia de adecuación ambiental de las propiedades rurales para fines de empréstitos subsidiados.

La legitimación vino del discurso oficial justificando que los cambios eran necesarios para los pequeños propietarios con amenazas a la supervivencia si tenían que recuperar y mantener la vegetación nativa en la propiedad. A pesar de ser usados dichos propietarios como fuerza legitimadora de retroceso, los principales beneficiados fueron los grandes propietarios, que controlan la mayor parte de las tierras de cultivo, porque la Ley concedió amnistía a todos los crímenes ambientales asociados al desmantelamiento realizado en 2008.

Además del vacío legal que una decisión de esa envergadura provoca, fueron flexibilizados los parámetros de protección ambiental donde la conservación deja de ser una imposición inseparable del derecho de la propiedad privada (Marés, 2003). Al ser restaurada la prerrogativa de los servicios ambientales, se indemniza a quienes conservan la vegetación nativa, y se elimina, en la práctica, el principio constitucional de función

${ }^{2}$ Los artículos 43, 48, 51 y 53 definen como crimen el retiro de vegetación en áreas de preservación permanente y de reserva legal y determinan el registro de zonas intocables en la Notaría del Registro de la Propiedad.

${ }^{3}$ Decretos de Ley 6686/2008; 7029/2009; 7497/2011 y 7640/2011. 
social de la tierra. Bajo esos términos, lo que antes se concebía como bien común en la legislación brasileña, ya que ningún propietario tenía derecho a deforestar más allá de una proporción ambientalmente segura, fue convertido en mercancía, a ser pagada por la sociedad para que se garantice el mantenimiento de equilibrio de los ecosistemas indispensables para toda forma de vida.

Se entiende que tal desenlace es explicado por la ausencia de correlación de fuerzas en una sociedad y no de una relación simple, como se ha hecho saber, entre la densidad económica y poblacional, porque solamente 15.6 por ciento de la población brasileña vive en el campo (IBGE, 2010) y apenas 6.5 por ciento del PIв es proveniente del sector agropecuario (CePeA, 2014). Más bien, las economías capitalistas con tales características se sustentan en alianzas entre propietarios rurales y empresarios urbanos, algo semejante a lo identificado por Kay (2009).

En el caso brasileño, la tesis del capitalismo rentista clarifica los matices de esta alianza donde el sector agrario arcaico es parte constitutiva de los sectores dinámicos de la economía (De Souza, 1994; Umbelino, 2003), expresado en casos como el de la propiedad Curúa, en que el propietario impostor no sólo pertenece a los 100 hombres más ricos del mundo, sino también es fundador de C.R. Almeida, considerada la sexta mayor empresa de la industria de la construcción civil en el país en 2010, en la categoría de liquidez general (Exame, 2010).

La coincidencia de nombres asociados a las extensas propiedades y a grandes negocios urbanos podría prolongarse considerablemente, porque se trata de una estrategia creada durante la dictadura militar para debilitar la lucha por la reforma agraria que había alcanzado su auge, al mismo tiempo en que estaban dadas las condiciones materiales para que la industrialización se consolidara. Simultáneamente prevalecía la idea de que sólo la industria podía promover el desarrollo, y aún es hegemónica, pese a la disidencia expresada en reacciones que no cuentan con proyección a causa del férreo control de clase sobre el aparato de Estado y los medios de comunicación. 
De cualquier modo, está establecido un contradiscurso que, más allá de los puntos de referencia del desarrollo alternativo, evoca a una alternativa del desarrollo (Houtart, 2010). Se trata de un nuevo movimiento que requiere, una vez más, de un amplio esfuerzo de movilización y luchas sociales. Ya en el pasado fue posible gracias a la evidencia de que la base de la economía agroexportadora latifundista no fue capaz de garantizar la provisión de materia prima para el sector, al mismo tiempo en que se podía atribuir al monopolio de tierra el raquitismo del mercado interno, el mayor obstáculo de la dinamización de la economía capitalista; por eso, la reforma agraria aparecía como la salida urgente.

Sin cooptar a la burguesía urbana no habría sido posible evitarla y, para hacerlo, el Estado autoritario, visceralmente comprometido con las oligarquías, implementó una política de renuncia tributaria para las actividades urbanas cuyos empresarios se embarcaran en proyectos agropecuarios integralmente financiados por el gobierno. Con el pretexto de modernizar la agricultura para dar sustento a la industrialización, se transfirieron vastas extensiones de tierras públicas a tal segmento, lo cual apenas una parte era característicamente burguesa, dada la histórica contribución de clase dentro de la economía agroexportadora, que tiene en las actividades urbanas una diversificación de negocios, de ahí su fuerte identidad de clase.

La maniobra que forjó la alianza tierra-capital (De Souza, 1994) proporcionó el cierre de la brecha emancipatoria con la adhesión de quienes ahora tienen en la tierra una forma nueva de patrimonio de bajo costo y libre de riesgo. En su interior, se implantó un proyecto de modernización conservadora, que se refleja en indicadores diametralmente opuestos: de un lado, prominencia económica, del otro, desigualdad social. Eso echaría raíces dentro de las veinte más grandes economías del mundo, ya que Brasil es el segundo país más desigual, incluso cuando se compara la participación del 10 por ciento más pobre en la renta nacional, pasa a primera posición, siendo que la mayor parte está en el campo (охғам, 2012). 
Para eso, es insuficiente o inexistente la tierra que se le atribuye a la vulnerabilidad extrema. Conforme a lo detallado en la Tabla 1, los productores cuyas áreas son menores a 10 hectáreas y que corresponden a 52.8 por ciento de los agricultores brasileños, tienen una media inferior a 2.9 hectáreas y una producción promedio, en valor por hectárea, de $\mathrm{R} \$ 2,793.20$ (\$1,019.73 USD). Por el otro lado, el área promedio de las propiedades con extensión superior a mil hectáreas es de 3,155 hectáreas, con una producción promedio por hectárea de $\mathrm{R} \$ 309.12$ (\$112.85 USD) (Tomiasi, 2014).

Tabla 1

Distribución de tierras según Censo Agropecuario, Brasil (hectáreas)

\begin{tabular}{|c|c|c|}
\hline \multicolumn{2}{|l|}{ Área territorial de Brasil } & $853^{`} 363,612$ \\
\hline \multicolumn{2}{|l|}{ Reservas indígenas } & $125^{\prime} 545,870$ \\
\hline \multicolumn{2}{|l|}{ Reservas ambientales } & $72^{\prime} 099,864$ \\
\hline \multicolumn{2}{|l|}{ Área con cuerpos de agua } & $11^{\prime} 455,300$ \\
\hline \multicolumn{2}{|l|}{ Área urbanizada } & $2^{\prime} 073,700$ \\
\hline \multicolumn{2}{|c|}{ Total de área no imputable a propiedades agropecuarias } & $211^{\prime} 174,734$ \\
\hline \multicolumn{2}{|l|}{ Área declarada por propiedades agropecuarias } & $333^{\prime} 679,147$ \\
\hline \multicolumn{2}{|l|}{ Área omitida por propiedades agropecuarias } & $308^{\prime} 509,731$ \\
\hline \multicolumn{2}{|l|}{ Total área imputable a propiedades agropecuarias } & $642^{\prime} 188,878$ \\
\hline ESTRUCTURA AGRARIA SEGÚN DIMENSIONES DECLARADAS & $\begin{array}{l}\text { No. DE UNIDADES AGRíCOLAS } \\
\text { (PROPIEDADES) }\end{array}$ & ÁREA \\
\hline Hasta 10 has & $2^{\prime} 732,170$ & 7’798,777 \\
\hline 10 a 100 has & $1^{\prime} 971,600$ & $62^{\prime} 893,978$ \\
\hline 100 a 1000 has & 424,288 & $112^{\prime} 844,186$ \\
\hline Más de 1000 has & 47,578 & $150^{\prime} 143,096$ \\
\hline Total declarado por propiedades & $5^{\prime} 175,636$ & $333^{\prime} 679,147$ \\
\hline
\end{tabular}

Fuente: IBGE, 2009. 
En promedio, cada gran propiedad ocupa un área correspondiente a 1,104 pequeñas, indicador de una relación asimétrica, porque ese cálculo considera apenas las tierras declaradas en exploraciones agropecuarias, donde más de 308.5 millones de hectáreas fueron omitidas por los propietarios; el Censo contabiliza solamente 333.6 millones como área de dominio privado, cuando en realidad es de más de 642 millones. Como se detalla en la Tabla 1, el Instituto Brasileño de Geografía y Estadística (Instituto Brasileiro de Geografia e Estatística, IBGE) utilizó la expresión área con otras ocupaciones (IBGE, 2009: 100) que cubre todos los usos posibles. En realidad, la definición fue una salida política encontrada por el órgano para no explicar la dimensión del fraude involucrado en las tierras en el país y donde desaparecieron de las cuentas oficiales nada menos que 48.1 por ciento de ellas.

Como la legislación prescribe la desapropiación para grandes propiedades, y sólo en el caso de que fueran improductivas o no cumplieran con la legislación ambiental o laboral, se supone que la pertinencia de ocultar la dimensión real de las propiedades al declarar para el Censo se debe a que es mayor a ese estrato. Lo mismo sucede para el acaparamiento de tierras, porque la legislación reconoce el establecimiento de propiedades de hasta 100 hectáreas en tierras públicas y dispone mecanismos de regularización. Se distingue del acaparamiento porque se trata de áreas consideradas productivas por el trabajo de la familia y debe, por tanto, proporcionar sus medios de vida (Ley 6383/1976). Es por eso que los conflictos más violentos están ocurriendo en el Amazonas, región que concentra las unidades de conservación, áreas indígenas y tierras públicas todavía identificables, sobre las cuales el uso campesino puede ser legitimado por la ley.

$\mathrm{Al}$ menos que la información dada al Censo Agropecuario pudiesen repercutir directamente sobre los declarantes, se trata de un levantamiento oficial que, al depender de la composición de las fuerzas políticas, pudiera amenazarlos, como aconteció en el caso de la legislación ambiental. Por eso, en ese o en los censos anteriores, la declaración de propiedad hace tiempo que se habría considerado como fuera de la ley. 
La fracción desaparecida como expresión del territorio nacional tiene mucho que decir sobre el acaparamiento de tierras públicas como parte constitutiva de la gran propiedad y sus modalidades de acumulación de capital.

Es cierto que tales vulnerabilidades inquietan a la oligarquía y al aparato institucional a su servicio; conscientes de que la legitimación de sus prácticas, la condición para su perpetuidad en cuanto a clase hegemónica, depende fundamentalmente de que se omita o que se afirme su perfil productivo así como su respectiva importancia económica para la nación. La falsificación de información continuará siendo un expediente válido en cuanto a integración del banco de datos a favor de la transparencia sobre la situación real de la tierra y de la producción de Brasil como una posibilidad técnica, pero sin ninguna posibilidad política de ser efectuada.

Aunque el incremento proveniente de las innovaciones técnicas sea una realidad en todas las actividades rurales y deba ser repasado periódicamente, como previó la Ley 8629/1993, estratégicamente no han cambiado desde inicios de la década de los años ochenta, cuando el padrón técnico en la agricultura era incipiente y la productividad muy baja. Como la improductividad es el motivo principal capaz de llevar la desapropiación para fines de la reforma agraria y obligatoriamente debe ser medida en las propiedades que se convierten en objeto de litigio por los campesinos en lucha, la estrategia ha sido mantener los valores de referencia bajos o suficientes para que la legalidad sea medida como utilización ínfima de tierras.

En los últimos treinta años, la única tentativa de actualización de los índices de productividad aconteció en 2006, después de concluidos los estudios del Ministerio de Desarrollo Agrario, que en esa ocasión propiciaron un reajuste de 30 por ciento. Aunque eso fuese absolutamente insuficiente para atenuar las distorsiones derivadas del aumento promedio de la productividad en las tres décadas anteriores, estimado en 300 por ciento, la articulación de los ruralistas se concentró en el Ministerio de Agricultura, que se ha negado a validar el cambio en esa ocasión, y 
no ha sucedido hasta el momento, aunque desde 2010 se tramitó una Acción Civil Pública interpuesta por el Ministerio Público Federal para que eso ocurra (MPF, 2010).

Eso sucedió en los casos en que miembros de la justicia brasileña recurrieron a instrumentos jurídicos para frenar las irregularidades al interior del Estado, hecho que revela cuán contradictorio es, de ahí la necesidad de analizarlo desde el prisma de la hegemonía, donde las contradicciones de clase se expresan en la estratégica combinación entre agilidad y lentitud institucionales conforme al contenido de estancamiento y correlación de fuerzas en confrontación.

Prueba de ello es que poco se avanzó con respecto a la Ley 10267/2001, que regula las acciones de la Notaría del Registro de la Propiedad, un servicio privado y descentralizado que, paradójicamente, ejerce el control de la situación jurídica de todas las tierras del país. Por eso, las únicas informaciones precisas que existen sobre las tierras privadas $y$, consecuentemente, públicas, están dispersas por los 5,564 municipios donde, a menudo, existen varios registros.

Esa pulverización, que continúa siendo la principal aliada del acaparamiento en Brasil, resulta ser un vicio de origen cuando se instauró la República. Con todo, su persistencia se explica menos por las dificultades prácticas del Estado para tomar para sí el control de tales informaciones que por la conveniencia política de renuncia, dado que en los registros los fraudes con tierras públicas son consumados, entonces sólo largas batallas judiciales pueden restaurarlas. Por ello toda la información pública disponible sobre la propiedad de la tierra está basada en la autodeclaración de quien la controla, siendo una inconsistencia de los datos oficiales, como el caso del Censo Agropecuario.

La combinación entre inercia y benevolencia institucional y el escenario propicio para el no cumplimiento de la función social de la propiedad rural impone marcas territoriales muy profundas en la concentración de la tierra y la dependencia de los lugares para con las actividades primarias, porque, más allá de los grandes propietarios que están generalmente ausentes, implica inyectar en otros lugares ingresos 
obtenidos, lo cual no genera empleos y la incipiente renta circulante en pequeñas ciudades.

Esto provoca el deshilacho del tejido social en regiones donde el sector industrial y de servicios es poco dinámico, pues en la mayor parte del año la fuerza de trabajo económicamente activa está desocupada, incapaz de movilizar la economía local. Existe un colapso en contenido con políticas sociales compensatorias que, aunque imprescindibles en el plano inmediato, a mediano y largo plazo no se traducen en desarrollo porque los individuos beneficiados son despojados de las condiciones concretas de protagonizar su devenir.

Esa modalidad de socialización de pérdidas impuesta por la oligarquía resume el pasivo ambiental, sobre el cual todavía poco se habla en términos monetarios, porque es difícil contabilizar impactos de larga duración, muchos de los cuales son irreversibles. Aunque las prácticas predatorias sean extensivas a todos los estratos de propiedad, los titulares de áreas extensas cuyo dominio legal fue defraudado o puede ser cancelado por razones de improductividad, tienden a extraer lo máximo en recursos naturales con el mínimo de inversión, de ahí que se trata de un negocio cuya rentabilidad está fundada en la depredación.

Esa lógica explica la deforestación a tasas incompatibles con el uso productivo de la tierra, siendo ejemplar el del Amazonas Legal, donde se destinó apenas 4.9 por ciento del área deforestada para cultivos en 2008 (EMBRAPA-INPE, 2011). Lo mismo se trata del índice inferior al que se tiene en las regiones donde la población está consolidada, el problema es general en todo el país: el IвGE estimó en 52.7 millones de hectáreas el área con cultivos temporales, equivalente a 8.7 por ciento del área con propiedad declarada (InCra, 2013). Para el Banco Mundial, ese porcentaje sería 8.1 por ciento ( $\mathrm{wB}, 2010$ ). Esos son signos de ociosidad/improductividad excepcional en un país donde la eficiencia en la agricultura está asociada a la gran propiedad, pretexto capaz de cubrir la dimisión del Estado a las políticas territoriales inclusivas, como la de la Reforma Agraria. 
La opción explícita por un concepto de desarrollo complaciente, que favorece al monopolio de tierra, es portadora de un grave cobro a la sociedad, a veces manifestado de inmediato, a veces expresado en vulnerabilidad socioambiental de difícil reversión. Actualmente, las principales evidencias son la flexibilización de la legislación ambiental y la tentativa de destrucción de los marcos protectores de territorios indígenas y de comunidades tradicionales, para que más tierra alimente el molino satánico de la acumulación, para utilizar la expresión de Polanyi (1980: 86) que condiciona inclusive el derecho a la existencia de incontables formas de vida de dividendos acumulados en forma de renta del suelo.

\section{CONSIDERACIONES FINALES}

En tiempos donde una de las palabras de orden en la agenda internacional es la necesidad de reducir la pobreza, se hace necesario traer a colación elementos teóricos y empíricos que desnuden las intenciones vacías y favorezcan acciones prácticas. Eso requiere de la comprensión de los puntos muertos y obstáculos que necesariamente se manifiestan en el interior de los Estados-nación, porque es, en esa escala, donde son ejecutadas las acciones cuyos desarrollos territoriales determinan los patrones de inclusión y las tasas de exclusión social.

Lo relevante de Brasil se debe menos a su posición territorial, demográfica y económica y más a sus avances alcanzados en los últimos años en reducción de la pobreza, cuyos resultados positivos se pueden disolver al mantener en el poder a la oligarquía para imponer una agenda en esencia disipadora de derechos y garantías fundamentales, que incluye tanto la dimensión ambiental como la humana.

La acción con particular eficacia tras bastidores del Estado ha conseguido imponer la disminución de normas jurídicas protectoras del bien común y éstas fueron conquistadas de la manera más dura por esa 
sociedad marcada por el autoritarismo umbilicalmente alimentado por la tradición oligárquica.

Ejemplo de ello es el cambio en el Código Forestal Brasileño, con una legislación ambientalmente innovadora; explícitamente se convierte en el referendo sobre los crímenes ambientales pasados y sutilmente se torna en un instrumento de anulación de la función social de la tierra, principio constitucional estructural de cualquier Estado de derecho.

Otra investida al Estado de derecho tiene que ver con la Propuesta de Enmienda Constitucional (2000) que otorga capacidad al Poder Ejecutivo de destituir la incumbencia de demarcar y responder por la integridad de los territorios indígenas (PEC 215/2000). Esas atribuciones debieron haber pasado por el Parlamento, que es mayoritariamente ruralista y está ávido de legalizar tierras ya invadidas y reclamadas como si fueran propiedad privada. Todo indica que serán ampliados los márgenes legales para el despojo de los territorios ya reconocidos, ahora en litigio, gracias a un Poder Judicial absolutamente cómplice de los actos de los poderosos de la tierra.

Por más que se invoque la justificación del amplio beneficio económico del país, se ha legitimado la apropiación empresarial de las tierras, en tanto el argumento de los ruralistas es la necesidad de la seguridad jurídica para producir en el campo; en la práctica, el objetivo es la regulación de títulos de propiedad actualmente no válidos. La conversión de la propiedad acaparada en jurídicamente reconocida es condición previa para su ingreso en el circuito de mercancías, para así completar el de renta capitalizada, modalidad de la acumulación por desposesión que está en el corazón del capitalismo en Brasil.

Ya que el saldo económico de esa transferencia pudiese ser importante, vía la ampliación de áreas intensivamente cultivadas, en las evidencias indican que no lo será, por que no puede reducir la pobreza o la desigualdad, que son partes del mismo problema. Como reconoció la Organización de las Naciones Unidas, cuanto más altos los niveles de desigualdad, más difícil será reducir la pobreza (UNRISD, 2010). Por eso 
los países pobres son más desiguales y, vale recordar, dentro de ellos, Brasil es el primero.

La concentración de tierras ha sido decisiva, y explica la forma cómo la tierra está apropiada sin el respeto a la agricultura y a sus agricultores, y se constituye en problema primario del proceso de acumulación del capital; de ahí su centralidad en la actualidad. Se reafirma la necesidad de estudios que promuevan una mirada atenta a los procesos en curso en el campo, con el fin de que sea recolocada en la agenda política la pertinencia de la profunda reestructuración agraria, compatible con los desafíos de conservación ambiental, con respeto a los territorios indígenas y tradicionales, y en contra de la eliminación de barreras a la plena realización de las potencialidades productivas del campesinado.

Eso significa confrontarse con el poder de acción del latifundio, en gran medida apoyado en la representación dualista, particularmente en la academia, que se resume en el presupuesto de la eficiencia y protagonismo económico de la gran propiedad en oposición a la supuesta incapacidad económica de los productores asociados por sus tierras y recursos insuficientes más que, conforme a los datos aquí expuestos, por haber demostrado un desempeño proporcionalmente excepcional.

Las estrategias de producción académica y reproducción social no típicamente capitalistas, en lugar de presentarse como un lastre del pasado, son una reserva insustituible para el futuro de la civilización como pregonan Mazoyer y Roudart (2010), donde no hay desprecio por la urgencia de democratizar la tierra, el otro nombre que se le dio a la naturaleza, diría Polanyi (1980).

\section{REFERENCIAS}

Centro de Estudios Avançados em Economia Aplicada (cepea) (2014), рIв do agronegócio, en http://www.cepea.esalq.usp.br/pib (consultado el 10 de agosto de 2014). 
Comissão Pastoral da Terra (СРт) (2011), Conflitos no campo no Brasil 2010, Goiânia.

De Souza, Jose (1994), O poder do atraso, São Paulo, Hucitec.

Diário Oficial da União (1976), »Lei 6.383/1976. Dispõe sobre o processo discriminatório de terras devolutas da União e dá outras providências», Brasilia, 9 de diciembre.

(1988), «Lei 9.605/1998. Dispóe sobre as sanções penais e administrativas derivadas de condutas e atividades lesivas ao meio ambiente, e dá outras providências», Brasilia, en http://www.ibama.gov.br/fauna/legislacao/ lei_9605_98.pdf (consultado el 28 de diciembre de 2010).

(1993), «Lei 8.629/1993. Dispóe sobre a regulamentação dos dispositivos constitucionais relativos à reforma agrária», Capítulo III, Título VII.

(2002), «Lei 10.267/2001. Dispõe sobre a obrigatoriedade de georreferenciamento de todas as propriedades rurais e dá outras providências», Brasilia, 30 de octubre.

(2008), «Decreto 6.514. Dispõe sobre as infrações e sanções administrativas ao meio ambiente, estabelece o processo administrativo federal para apuração destas infrações, e dá outras providências», Brasilia, 22 de julio, en http://www.mma.gov.br/estruturas/imprensa/_arquivos/regulamento_lei_ crimes_ambie ntais.pdf (consultado el 20 de marzo de 2011).

(2008a), «Decreto 6.686. Altera e acresce dispositivos ao Decreto 6.514, de 22 de julho de 2008, que dispóe sobre as infrações e sanções administrativas ao meio ambiente e estabelece o processo administrativo federal para apuração destas infrações», Brasilia, 10 de diciembre, en http://www.planalto.gov.br/ ccivil_03/_ato2007-2010/2008/decreto/d6686.htm (consultado el 4 de febrero de 2011).

(2009), «Lei 11.952/2009. Dispõe sobre a regularização fundiária das ocupações incidentes em terras situadas em áreas da União, no âmbito da Amazônia Legal; altera as Leis 8.666/ 1993 e 6.015/1973; e dá outras providências», Brasilia, 25 de junio.

(2009a), «Decreto 7.029. Institui o Programa Federal de Apoio à Regularização Ambiental de Imóveis Rurais, denominado »Programa Mais Ambiente», e dá outras providências», Brasilia, 11 de diciembre, en http://www.planalto.gov.br/ccivil_03/_Ato2007-2010/2009/Decreto/D7029.htm (consultado el 18 de febrero de 2011).

(2011), «Decreto 7.497. Dá nova redação ao artigo 152 do Decreto 6.514, de 22 de julho de 2008, que dispõe sobre as infrações e sanções administrativas 
ao meio ambiente e estabelece o processo administrativo federal para apuração destas infrações», Brasilia, 9 de junio, en http://www.planalto.gov.br/ccivil_03/_Ato2011-2014/2011/Decreto/D7497.htm (consultado el 18 de septiembre de 2011).

(2011a), «Decreto 7.640. Altera o art. 152 do Decreto 6.514, de 22 de julho de 2008, que dispõe sobre as infrações e sanções administrativas ao meio ambiente e estabelece o processo administrativo federal para apuração destas infrações», Brasilia, 9 de diciembre, en http://www.planalto.gov.br/CCIVIL_03/_Ato2011-2014/2011/Decreto/D7640.htm (consultado el 23 de febrero de 2012).

(2012), «Lei 12651/2012. Dispõe sobre a proteção da vegetação nativa; Altera as Leis 6.938, de 31 de agosto de 1981, 9.393, de 19 de dezembro de 1996, e 11.428, de 22 de dezembro de 2006; Revoga as Leis 4.771, de 15 de setembro de 1965, e 7.754, de 14 de abril de 1989, e a Medida Provisoria 2.166- 67, de 24 de agosto de 2001; e dá outras providências», Brasilia, 28 de mayo.

Empresa Brasileira de Pesquisa Agropecuária e Instituto Nacional de Pesquisas Espaciais (embrapa-inpe) (2011), Levantamento de informações de uso e cobertura da terra na Amazônia, Belém, en http://www.inpe. $\mathrm{br} / \mathrm{cra} /$ projetos_pesquisas/sumario_executivo_terraclass_2008.pdf (consultado el 2 de junio de 2012).

Exаме (2010), Maiores empresas por liquidez geral em 2010, en http://exame.abril. com.br/negocios/melhores-emaiores/empresas/maiores/1/2010/liquidezgeral/-/industria-da-construcao/-/-? (consultado el 18 de julio de 2012).

Food and Agriculture Organization of United Nations (fao) (2010), Fao Statistical Yearbook, World Food and Agriculture, Roma, en http://www. fao.org/docrep/015/am081m/am081m00.htm (consultado el 14 de junio de 2012).

Fraga, Nilson (2010), Vale da Morte: o Contestado visto e sentido, Blumenau, Hemisfério Sul.

Galeano, Eduardo (1989), As veias abertas da América Latina, núm. 29, Río de Janeiro, Paz e Terra.

Gonçalves, Sandra (2012), A questão agrária no Brasil e a bancada ruralista no congresso nacional, São Paulo, Universidade de São Paulo.

Governo Federal do Brasil (1988), Constituição da República Federativa do Brasil, Brasilia, 25 de febrero.

Harvey, David (2013), Os limites do capital, São Paulo, Boitempo. 
Houtart, François (2010), A agroenergia: solução para o clima ou saída da crise para o capital, Petrópolis, Vozes.

Instituto Brasileiro de Geografia e Estatística (ibge) (2009), Censo Agropecuário 2006, Río de Janeiro.

(2010), Censo Populacional 2010, Primeiros resultados, Rio de Janeiro, en http://www.ibge.gov.br/estadosat/perfil.php?sigla=mt (consultado el $12 \mathrm{de}$ febrero de 2011).

(2014), Sistema IBGE de Recuperação Automática, Rio de Janeiro, en http:// www.sidra.ibge.gov.br (consultado el 4 de abril de 2014).

Instituto Nacional de Colonização e Reforma Agrária (incra) (2013), Sistema Nacional de Cadastro Rural, Estatísticas Cadastrais Situação Jurídica 2013, Brasilia.

Kautsky, Karl (1980), A questão agraria, São Paulo, Proposta.

KaY, Cristobal (2009), «Development Strategies and Rural Development: Exploring Synergies, Eradicating Poverty», The Journal of Peasant Studies, vol. 36, núm.1, pp. 103-137.

Marés, Carlos (2003), A função social da terra, Puerto Alegre, Safe.

Marx, Karl (1974), O capital, Río de Janeiro, Civilização Brasileira.

Mazoyer, Marcel y Laurence Roudart (2010), História das agriculturas no mundo: do neolítico à crise contemporânea, São Paulo, UnesP.

Ministério Público Federal (MPf) (2010), Ação civil pública pela atualização dos Indices de Produtividade, en http://www.prdf.mpf.gov.br/imprensa/arquivos_noticias/acp-indices-produtividade.pdf (consultado el 20 de junio de 2012).

Monteiro, Lúcia (2014), Preços de terras em Goiás subiram 323\% em 12 anos, en http://www.radioriovermelho.com.br/site/noticia.php?id=8976 (consultado el 24 de septiembre de 2014).

Oxford Committee for Famine Relief (oxfam) (2012), Left behind by the G20?, en http://www.oxfam.ca/sites/default/files/Left\%20behind\%20 by $\% 20$ the\%20G20\%20Oxfam\%20Report.pdf (consultado el 7 de agosto de 2012).

Pinto, Lúcio (2011), A maior propriedade rural do mundo deixou de existir legalmente, en http://www.maranhaonews.com/meio-ambiente/meioambiente/37-meioambiente/2036-a-maior-propriedade-rural-domundo-deixou-de-existir-legalmente.html (consultado el 2 de agosto de 2012). 
Polanyi, Karl (1980), A grande transformação: as origens da nossa época, Río de Janeiro, Campus.

Propuesta de Enmienda Constitucional (2000), pec 215/2000. Proposta de Emenda Constitucional. Transfere a competência da União na demarcação das terras indígenas para o Congresso Nacional e possibilita a revisão das terras já demarcadas, en trámite.

Secretaria da Receita Federal do Brasil (srfb) (2001), Relatório da grilagem de terras públicas na Amazônia, en http://pt.scribd.com/doc/33421741/ Relatorio-Final-CPI-Terras-Amazonas-grilagem (consultado el 26 de julio de 2012).

Tomiasi, Eliane (2014), «The Agricultural, Environmental and Socio-political Repercussions of Brazil's Land Governance System», Land Use Policy, núm. 36, pp. 134-144.

Umbelino, Ariovaldo (2003), «Barbárie e Modernidade: as transformações no campo e o agronegócio no Brasil», Terra Livre, vol. 21, pp. 113-156. (2010), »A questão da aquisição de terras por estrangeiros no Brasil», Agrária, vol. 12, pp. 3-113.

United Nations Research Institute for Social Development (unrisd) (2010), «Combating Poverty and Inequality», Policy Brief, núm. 1.

Wolf, Eric (1976), Las luchas campesinas del siglo xx, México, Siglo XXI Editores. World Bank (шв) (2010), Indicator: Agriculture and Rural Development, en http://data.worldbank.org/indicator (consultado el 12 de agosto de 2012). 